\title{
AFFECTIVE TEMPERAMENT AND SEASONALITY IN BIPOLAR DISORDER
}

\author{
Kürșat Altınbaș ${ }^{1}$, Bahri İnce ${ }^{2}$ \& Sinan Gülöksü̈z, \\ ${ }^{1}$ Mazhar Osman Mood Clinic, Department of Psychiatry, Selçuk University Medical School, Konya, Turkey \\ ${ }^{2}$ Rasit Tahsin Mood Clinic, Bakırköy Research and Training Hospital for Psychiatry, \\ Neurology and Neurosurgery, Istanbul, Turkey \\ ${ }^{3}$ Department of Psychiatry, Maastricht University, Maastricht, Netherlands \\ ${ }^{4}$ Department of Psychiatry, Yale University School of Medicine, New Haven, US
}

received: 14.5.2018;

revised: 30.8.2018;

accepted: 25.9.2018

\section{SUMMARY}

Background: Both affective temperaments and seasonality impact on the illness course in bipolar disorder (BD). This exploratory study aims to investigate the link between seasonality and affective temperament in $B D$.

Subjects and methods: Sixty-six euthymic patients with BD-I were recruited. The Seasonal Pattern Assessment Questionnaire (SPAQ) and Temperament Evaluation Memphis, Pisa, Paris and San Diego-Autoquestionnaire version scale (TEMPS-A) were applied.

Results: The seasonal BD rate was 39.4\% $(n=26)$. Depressive and anxious temperament scores were higher in patients with seasonality. The SPAQ total scores were also associated with depressive, cyclothymic, and anxious affective temperament scores.

Conclusion: Our findings warrant further investigation to understanding the complex interaction between seasonality, mood regulation, and temperament collectively moderating illness course in $B D$. This study implies that affective temperament may have some value in discerning the link between seasonality and illness course in $B D$.

Key words: affective temperament - seasonality - bipolar disorder

$$
* * * * *
$$

\section{INTRODUCTION}

Illness course is often heteregenous in bipolar disorder (BD). The Descriptive and Statistical Manual of Mental Disorders fifth edition (DSM-5) offers several clinical specifiers for BD that may impact on the clinical course of illness: mixity, seasonality, and suicidality. Several studies, highlighting the importance of seasonality in BD, show a disturbed chronobiological rhythm during both acute episodes and inter-episodic periods (Geoffroy et al. 2014). Seasonal symptoms (syndromal and subsyndromal) were observed in about one-fifth of patients with BD (Melrose 2015, Pjrek et al. 2016). Numerous studies investigating the pattern of seasonal symptoms demonstrate that manic relapse is much more common in spring and summer, whereas depressive symptoms reach to a peak in early winter (Geoffroy et al. 2014). Few studies exploring the role of seasonality in mixed episode based on the previous DSM definition found a peak in spring and summer (Lee et al. 2007, Yang et al. 2013). There was also reported significant seasonal variations of symptoms such as cognitive functions, psychosis, aggressiveness and suicidality in bipolar patients (Geoffroy et al. 2014). Overall, abundant evidence from different geographical regions implies that seasonal pattern may be linked to a more severe illness course including earlier age at onset, more mood episodes, rapid cycles among patients with BD (Geoffroy et al. 2014).
Affective temperament is strongly associated with mood disorders, particularly $\mathrm{BD}$, with a significant impact on illness course (Solmi et al. 2016). Hyperthymic temperament might be protective against suicide (Vazquez et al. 2010), whereas irritable and cyclothymic temperaments were associated with worse functioning (Walsh et al. 2012).

Moreover, in a recent study, affective temperament, chronotype and specific circadian gene polimorphisms were found to be associated in a non-clinical sample (Jankowski \& Dmitrzak-Weglarz 2017). In this regard, incorporating findings, we hypothesized that seasonality and affective temperament, both acting as determinants for illness course in BD, would be associated. Therefore, this exploratory study aimed to investigate whether there was an association between affective temperament scores and seasonality in patients with BD-I.

\section{SUBJECTS AND METHODS}

\section{Study Population}

Sixty-six patients with BD-I, followed at Rasit Tahsin Mood Disorders Outpatient Unit of Bakırköy Research and Training Hospital for Psychiatry, Neurology, Neurosurgery, were recruited consecutively. The diagnosis was confirmed by two separate clinicians conducting DSM-IV-based interviews and evaluating 
standardized medical records that have been in use at SKIP-TURK (a nation-wide mood disorders follow-up program) (Tirpan et al. 2004). Patients were euthymic with total scores of Young Mania Rating Scale (YMRS) and 17 items Hamilton Depression Rating Scale (HAMD) below 7. Exclusion criteria were: age above 18 or below 65 years, illiteracy, current diagnoses of alcohol and substance use disorder, mental retardation, dementia, and decline in cognitive functioning that can impair understanding of the self-rated scales. The Medical Ethics Committee of Bakırköy Research and Training Hospital for Psychiatry, Neurology, and Neurosurgery approved the study protocol, and the study was carried out in accordance with the Declaration of Helsinki. Written informed consent was obtained from all the participants prior to enrollment.

\section{Assessment Tools}

Demographic data and health information were collected by a self-administered survey which was developed by the researchers. Each patient's clinical features and treatment history of BD were also evaluated. Patients were evaluated for seasonality using the Seasonal Pattern Assessment Questionnaire (SPAQ) (Noyan et al. 2000) and affective temperamental features using the Temperament Evaluation Memphis, Pisa, Paris and San Diego-Autoquestionnaire version scale (Vahip et al. 2005).

\section{Statistics}

STATA version 12.0 (STATA Corporation, College Station, TX, USA) was used to carry out the statistical analyses. Both visual (probability plot and histogram) analytical approaches (Shapiro-Wilk test) were applied to ascertain normality. $\mathrm{T}$ test and Chi-square test were used to compare demographic and illness characteristics between groups. As the sample size was small and the distributions were skewed, we cautiously applied the distribution-free method of bootstrapping to each regression analysis $(n=10.000)$ analyzing associations between seasonality (SPAQ score) and affective temperaments (TEMPS-A scores). Analyses were also adjusted for age, sex, and age of onset. Statistical significance was set at $\mathrm{p}<0.05$.

Table 1. Sample characteristics

\begin{tabular}{|c|c|c|c|c|c|}
\hline & $\begin{array}{c}\text { Total } \\
(\mathrm{N}=66)\end{array}$ & $\begin{array}{l}\text { Seasonal } \\
(n=26)\end{array}$ & $\begin{array}{c}\text { Non-seasonal } \\
(\mathrm{n}=40)\end{array}$ & Test statistic & $\mathrm{p}$ \\
\hline \multicolumn{6}{|l|}{ Gender $^{\mathrm{a}}, \mathrm{n}(\%)$} \\
\hline Female & $42(63.6)$ & $15(57.7)$ & $27(67.5)$ & 0.65 & 0.42 \\
\hline Male & $24(36.4)$ & $11(42.3)$ & $13(37.5)$ & & \\
\hline \multicolumn{6}{|l|}{ Education $^{\mathrm{a}}, \mathrm{n}(\%)$} \\
\hline Primary & $29(43.9)$ & $8(30.8)$ & $21(52.5)$ & & \\
\hline High school & $22(33.3)$ & $12(46.2)$ & $10(25.0)$ & 3.81 & 0.15 \\
\hline University & $15(22.7)$ & $6(23.1)$ & $9(22.5)$ & & \\
\hline \multicolumn{6}{|l|}{ Index episode ${ }^{\mathrm{a}}, \mathrm{n}(\%)$} \\
\hline Hypomania/Mania & $31(47.0)$ & $11(42.3)$ & $20(50.0)$ & & \\
\hline Depression & $21(31.8)$ & $10(38.5)$ & $11(27.5)$ & 0.87 & 0.65 \\
\hline Unidentified & $14(21.2)$ & $5(19.2)$ & $9(22.5)$ & & \\
\hline \multicolumn{6}{|l|}{ Treatmenta, n(\%) } \\
\hline $\mathrm{Li} / \mathrm{VPA} / \mathrm{Li}+\mathrm{VPA}$ & $22(33.3)$ & $7(26.9)$ & $15(37.5)$ & & \\
\hline $\mathrm{Li}+\mathrm{SGA}$ & $18(27.3)$ & $6(23.1)$ & $12(30.0)$ & & \\
\hline $\mathrm{LI}+\mathrm{VPA}+\mathrm{SGA}$ & $13(19.7)$ & $6(23.1)$ & $7(17.5)$ & 10.6 & 0.22 \\
\hline VPA+SGA & $6(9.1)$ & $5(19.2)$ & $1(2.5)$ & & \\
\hline Other & $7(10.6)$ & $2(7.7)$ & $5(12.5)$ & & \\
\hline $\operatorname{Age}^{\mathrm{b}}, \operatorname{Mean}(\mathrm{SD})$ & $34.7(8.3)$ & $33.2(8.4)$ & $35.6(8.2)$ & 0.12 & 0.91 \\
\hline Age at onset ${ }^{\mathrm{b}}, \mathrm{Mean}(\mathrm{SD})$ & $23.3(7.5)$ & $22.2(9.4)$ & $24.1(6.1)$ & 0.71 & 0.48 \\
\hline Illness duration ${ }^{\mathrm{b}}$, Mean(SD) & $12.6(6.5)$ & $12.6(6.9)$ & $12.7(6.2)$ & 0.53 & 0.60 \\
\hline The SPAQ score ${ }^{\mathrm{b}}$, Mean(SD) & $9.7(4.7)$ & $14.1(2.4)$ & $6.9(3.4)$ & 4.51 & $<0.001$ \\
\hline \multicolumn{6}{|l|}{ Temperament $^{\mathrm{c}}$, Mdn. (Min-Max) } \\
\hline Depressive & $6.0(0-18)$ & $7.0(2-16)$ & $6.0(0-18)$ & 2.24 & $0.02 *$ \\
\hline Cyclothymic & $6.0(0-18)$ & $8.5(0-18)$ & $6.0(0-14)$ & 1.22 & 0.22 \\
\hline Hyperthymic & $8.0(1-18)$ & $8.5(2-17)$ & $8.0(1-18)$ & 0.16 & 0.87 \\
\hline Irritable & $4.0(0-16)$ & $4.5(0-16)$ & $3.0(0-16)$ & 0.06 & 0.95 \\
\hline Anxious & $5.0(0-21)$ & $6.5(0-19)$ & $5.0(0-21)$ & 2.18 & $0.03 *$ \\
\hline
\end{tabular}

${ }^{\mathrm{a}} \chi^{2}$ test; ${ }^{\mathrm{b}} \mathrm{T}$ test; ${ }^{\mathrm{c}}$ Mann-Whitney-U test: ${ }^{*} \mathrm{p}<0.05$ is statistically significant; Li:- lithium; VPA:- Valproate;

SGA - Second Generation Antipsychotic; Mdn - Median; SD - Standard Deviation; SPAQ - Seasonal Pattern Assessment Questionnaire 
Table 2. Associations between temperament dimensions and seasonality

\begin{tabular}{lcccccccc}
\hline & B & Bootstrap SE & $95 \%$ CI & p-value & B $^{*}$ & Bootstrap SE & $95 \%$ CI & p-value \\
\hline Depressive & 0.29 & 0.10 & $0.10 ; 0.49$ & 0.003 & 0.33 & 0.14 & $0.05 ; 0.61$ & 0.019 \\
Anxious & 0.28 & 0.09 & $0.10 ; 0.46$ & 0.002 & 0.27 & 0.12 & $0.03 ; 0.51$ & 0.029 \\
\hline
\end{tabular}

$\mathrm{CI}=$ Confidence Interval; $\mathrm{B}=$ Regression Co-efficient; $\mathrm{SE}=$ Standard Error; *Adjusted for age, sex, and age of onset

\section{RESULTS}

Table 1 summarizes sample characteristics. Twentysix patients (39.4\%) had higher scores than the SPAQ cut-off. There was no statistically significant difference between patients with and without seasonality in terms of gender, age, education level, age at onset, index episode, and illness duration. None of the patients had a rapid cycling illness course. Depressive and anxious temperament scores were higher in patients with seasonality (Table 1). Regression models were provided in Table 2. Regression models revealed that the SPAQ total scores were associated with depressive and axious temperament scores but not with those of irritable, cyclothymic and hyperthymic.

\section{DISCUSSION}

The main findings of this explorative study were: (i) Depressive and anxious temperament scores were significantly higher in patients with seasonal features; (ii) the SPAQ total scores were associated with the following affective temperament subtypes: cyclothymic, depressive, and anxious.

To our knowledge, this is the first study investigating the relation between affective temperament subtypes and seasonality, and therefore, requires replication in larger samples with a longitudinal design. Further, there is some evidence that the low sensitivity of the SPAQ cut-off score may result in exclusion of some cases (Mersch et al. 2014). Therefore, we also explored the relation between the continuous SPAQ total scores and cyclothymic affective temperament scores.

Previous work on defining particular characteristics of seasonal affective disorders (SAD), in relation to temperament and personality dimensions, reported discrepant findings. Using NEO (neuroticism, extroversion, openness to the experience) personality inventory, Bagby and colleagues reported higher Openness scores in patients with SAD than in those with nonSAD (Bagby et al. 1996). They also indicated this distinct group of patients as more imaginative, more emotionally sensitive and likely to entertain unconventional (Bagby et al. 1996). Another study, likewise, demonstrated that patients with seasonal depression had different temperament profiles than nonseasonal patients (e.g. lower scores on neuroticism-related symptoms), while non-seasonal depressive patients had much more extreme temperament features including trait anxiety and hostility (Pendse et al. 1999). In contrast, Gordon and colleagues (1999) failed to find a significant relationship between neuroticism, depression severity, and seasonality. Inconsistency in findings could be partly related with the broad definition of neuroticism as an approximation of experiencing mixed negative emotions that involve sadness, guilt, fear, anger, embarresment, sadness, impulsivity, and anxiety. Harm Avoidance (HA), one of the most studied temperament subtype, also refers to anticipatory worry, pessimism, intolerance to uncertainty in a narrow concept (Goel et al. 2003; Maeno et al. 2005). HA was associated with mood regulation and with seasonality (Goel et al. 2003, Chotai et al. 2004). In addition, high self-transcendence (ST) and high persistence (PS) were also correlated with the seasonal variation as measured by the SPAQ (Chotai et al. 2004).

Given the extent of agreement between the TEMPSA and the TCI-depressive, cyclothymic, anxious affective temperament subtypes were associated with HA; hyperthymic temperament with persistence (Rozsa et al. 2008). it is plausible to argue that our findings showing and association between the seasonality scores and the temperament scores (cyclothymic, depressive and anxious) might be in line with previous data (Rozsa et al. 2008, MacDonald et al. 2013). However, the variation in assessment tools using different definitions for measuring personality and temperament characteristics increases heterogeneity and precludes a comprehensive interpretation.

The social zeitgeber theory provides the framework to understand the dynamic interplay between mood symptoms and seasonal elements (Grandin et al. 2006). A growing body of evidence indicates affective temperament is strongly related to circadian activity and exposure to bright light (Goel et al. 2003, Rihmer et al. 2011). Accordingly, our findings also fall in the same direction - cyclothymic, depressive and anxious temperament scores were associated with the SPAQ scores. In this regard, we previously reported that temperamental dimensions constitute a vulnerability factor for the seasonal influence in a study investigating metabolic syndrome prevalence across affective temperament profiles (Altinbas et al. 2013). On the other hand, the SPAQ scores were associated with neither irritable nor hyperthymic temperament scores in the current study. It should be noted both hyperthymic and irritable temperament subtypes in particular have been linked to bipolar disorder (Solmi et al. 2016). Therefore, the lack of significance with these temperament subtypes in the current study might be explained by the size and the degree of homogeneity of the study 
sample comprising only patients with BD-I - resulting in a floor effect. Besides, predominance of the episode type should be considered as another limitation of our study considering the relationship between specific temperament type and the illness course since we did not include it to the statistical analysis. On the other hand, the sensitivity of the SPAQ is quite low that should be noted as an another limitation of the study.

\section{CONCLUSION}

This pilot investigation implies that temperamental characteristics may have some value in discerning the link between seasonality and BD. There is some evidence that the putative neurobiological mechanisms of seasonality, mood regulation, and temperament may be explained with shared molecular pathways and neurotransmitter systems underlying similar genetic background (Roecklein et al. 2013, Melrose et al. 2015). Our findings warrant further investigation to understanding the complex interaction between seasonality, mood regulation, and temperament collectively moderating illness course in $\mathrm{BD}$.

\section{Acknowledgements: None.}

Conflict of interest: None to declare.

\section{Contribution of individual authors:}

\section{CATEGORY 1}

Conception and design of study: Kursat Altinbas \& Sinan Guloksuz.

Data acquisition: Kursat Altinbas \& Bahri İnce.

Data analysis and interpretation: Bahri Ince \& Sinan Guloksuz

\section{CATEGORY 2}

Drafting manuscript: Kursat Altinbas, Bahri İnce \& Sinan Guloksuz.

Critical revision of manuscript: Kursat Altinbas, Bahri İnce \& Sinan Guloksuz.

\section{CATEGORY 3}

Final approval and accountability: Kursat Altinbas, Bahri İnce \& Sinan Guloksuz.

\section{References}

1. Altinbas K, Guloksuz S, Oral ET: Metabolic syndrome prevalence in different affective temperament profiles in bipolar-I disorder. Rev Bras Psiquiatr 2013; 35:131-135

2. Bagby RM, Schuller DR, Levitt AJ, Joffe RT: Seasonal and non-seasonal depression and the five-factor model of personality. J Affect Disord 1996; 38:89-95

3. Chotai J, Smedh K, Nilsson LG, Adolfsson R: A dual vulnerability hypothesis for seasonal depression is supported by the seasonal pattern assessment questionnaire in relation to the temperament and character inventory of personality in a general population. J Affect Disord 2004; 82:61-70

4. Geoffroy PA, Bellivier F, Scott J, Etain B: Seasonality and bipolar disorder: a systematic review, from admission rates to seasonality of symptoms. J Affect Disord 2014; 168:210-223

5. Goel N, Terman M, Terman JS: Dimensions of temperament and bright light response in seasonal affective disorder. Psychiatry Res 2003; 119:89-97

6. Gordon T, Keel J, Hardin TA, Rosenthal NE: Seasonal mood change and neuroticism: the same construct? Compr Psychiatry 1999; 40:415-417

7. Grandin LD, Alloy LB, Abramson LY: The social zeitgeber theory, circadian rhythms, and mood disorders: review and evaluation. Clin Psychol Rev 2006; 26:679-694

8. Henry C, Lacoste J, Bellivier F, Verdoux H, Bourgeois ML, Leboyer M: Temperament in bipolar illness: impact on prognosis. J Affect Disord 1999; 56:103-108

9. Jankowski KS, Dmitrzak-Weglarz M: ARNTL, CLOCK and PER3 polymorphisms-links with chronotype and affective dimensions. Chronobiol Int 2017; 34:1105-1113

10. Lee HC, Tsai SY, Lin HC: Seasonal variations in bipolar disorder admissions and the association with climate: a population-based study. J Affect Disord 2007; 97:61-69

11. MacDonald K, Berlow R, Thomas ML: Attachment, affective temperament, and personality disorders: a study of their relationships in psychiatric outpatients. J Affect Disord 2013; 151:932-941

12. Maeno N, Kusunoki K, Kitajima T, Iwata N, Ono $Y$, Hashimoto $S$, et al.: Personality of seasonal affective disorder analyzed by Tri-dimensional Personality Questionnaire. J Affect Disord 2005; 85:267-273

13. Melrose S: Seasonal Affective Disorder: An Overview of Assessment and Treatment Approaches. Depress Res Treat 2015; 2015:178564

14. Mersch PP, Vastenburg NC, Meesters Y, Bouhuys AL, Beersma DG, van den Hoofdakker RH, et al.: The reliability and validity of the Seasonal Pattern Assessment Questionnaire: a comparison between patient groups. J Affect Disord 2014; 80:209-219

15. Noyan MA, Elbi H, Korukoğlu S: The Turkish Version of Seasonal Pattern Assessment Questionnaire (SPAQ): A Reliability Study. Anatolian Journ Psychiatry 2000; 1:69-77

16. Pendse B, Westrin A, Engström G: Temperament traits in seasonal affective disorder, suicide attempters with nonseasonal major depression and healthy controls. J Affect Disord 1999; 54:55-65

17. Pjrek E, Baldinger-Melich P, Spies M, Papageorgiou K, Kasper S, Winkler D: Epidemiology and socioeconomic impact of seasonal affective disorder in Austria Eur Psychiatry 2016; 32:28-33

18. Rihmer Z, Erdos P, Ormos M, Fountoulakis KN, Vazquez $G$, Pompili $M$, et al.: Association between affective temperaments and season of birth in a general student population. J Affect Disord 2011; 132:64-70

19. Roecklein KA, Wong PM, Miller MA, Donofry SD, Kamarck ML, Brainard GC: Melanopsin, photosensitive ganglion cells, and seasonal affective disorder. Neurosci Biobehav Rev 2013; 37:229-239

20. Rózsa S, Rihmer Z, Gonda X, Szili I, Rihmer A, Ko N, et al.: A study of affective temperaments in Hungary: internal consistency and concurrent validity of the TEMPS-A against the TCI and NEO-PI-R. J Affect Disord 2008; 106:45-53 
21. Solmi M, Zaninotto L, Toffanin T, Veronese N, Lin K, Stubbs B, et al.: A comparative meta-analysis of TEMPS scores across mood disorder patients, their first-degree relatives, healthy controls, and other psychiatric disorders. J Affect Disord 2016; 196:32-46

22. Tirpan K, Ozerdem A, Tunca Z, Yazici O, Oral ET, Kurt E: A computerized registry program for bipolar illness in Turkey. J Affect Disord 2004; 78:126-127

23. Vahip S, Kesebir S, Alkan M, Yazici O, Akiskal KK, Akiskal HS: Affective temperaments in clinically-well subjects in Turkey: initial psychometric data on the TEMPS-A. J Affect Disord 2005; 85:113-125
24. Vazquez GH, Gonda X, Zaratiegui R, Lorenzo LS, Akiskal K, Akiskal HS: Hyperthymic temperament may protect against suicidal ideation. J Affect Disord 2010; 127:38-42

25. Walsh MA, Royal AM, Barrantes-Vidal N, Kwapil TR: The association of affective temperaments with impairment and psychopathology in a young adult sample. J Affect Disord 2012; 141:373-381

26. Yang AC, Yang CH, Hong CJ, Liou YJ, Shia BC, Peng $C K$, et al.: Effects of Age, Sex, Index Admission, and Predominant Polarity on the Seasonality of Acute Admissions For Bipolar Disorder: A Population-Based Study. Chronobiol Int 2013; 30:478-485

\section{Correspondence:}

Assoc. Prof. Kürşat Altınbaş, MD, PhD

Mazhar Osman Mood Clinic, Department of Psychiatry, Selcuk University Medical School, Alaeddin Keyklbat Campus Konya, Turkey

E-mail:kursataltinbas@gmail.com 